\section{Deletion Mutagenesis of Large (12-kb) Plasmids by a One-Step PCR Protocol}

BioTechniques 31:722-724 (October 2001)

Engendering deletions in genes and then assaying the functional consequences is a useful approach for mapping cis-acting regulatory elements. There are several different strategies for generating large deletions. One of the most convenient ways is to use two restriction enzymes to remove an internal fragment. However, in many cases, convenient enzyme sites are not available. Another approach is oligonucleotide-directed mutagenesis, in which a synthetic oligonucleotide lacking the sequence to be deleted is used $(7,8)$. Although this approach is a powerful method to introduce small deletions $(<5 \mathrm{nu}-$ cleotides), it cannot generate the larger deletions required for a wide variety of studies, including promoter mapping.

Here, we describe a convenient method that can generate large deletions. It involves using inverse PCR with two inverted tail-to-tail primers to amplify the entire plasmid except for the region to be deleted. This approach is powerful, as it makes precise deletions without requiring nearby restriction sites (4). The existing protocols based on this approach are applicable only to small $(<6-\mathrm{kb})$ plasmids $(4,5,9)$ (data not shown). Here, we improve on this method, thereby permitting deletion mutagenesis of large (12-kb) plasmids.

In our method, a pair of 5'-phosphorylated inverse primers separated by the region to be deleted is used for amplification. Compared with other protocols $(4,5,9)$, we provide three unique requirements for the primers. First, the primers must be purified by either PAGE or HPLC. We found that unpurified primers often introduced errors at the termini of PCR products (extra or deleted nucleotides) (data not shown). For our experiments, the oligonucleotides were purified by PAGE (SigmaGenosys, The Woodlands, TX, USA). Second, the two primers must be similar in size, as we found that if the primers differed by 10 nucleotides or more, then nucleotides were added or deleted at the ends of the PCR products. Third, each primer's melting temperature $\mathrm{T}_{\mathrm{m}}$ and length had to conform to specific requirements, as described below.

In our protocol, the PCR mixture contains $150 \mathrm{ng}$ of each primer (SigmaGenosys), $50 \mathrm{ng}$ template plasmid DNA, $200 \mu \mathrm{M}$ dNTPs, $2.5 \mathrm{U}$ PfuTurbo ${ }^{\mathrm{TM}}$ DNA polymerase (Stratagene, La Jolla, CA, USA), and the buffer supplied with the polymerase in a total volume of $50 \mu \mathrm{L}$. PCR was typically performed under the following conditions: denaturation at $95^{\circ} \mathrm{C}$ for 3 min, followed by 18 cycles of denaturation at $95^{\circ} \mathrm{C}$ for $45 \mathrm{~s}$, annealing at $62^{\circ} \mathrm{C}$ for $1 \mathrm{~min}$, and extension at $68^{\circ} \mathrm{C}$ for 2 $\mathrm{min} / \mathrm{kb}$ template. A portion of the PCR product $(5 \mu \mathrm{L})$ was then examined by agarose gel electrophoresis to determine whether the correct-sized product was obtained. The PCR product (45 $\mu \mathrm{L}$ ) was then incubated with $20 \mathrm{U} D p n \mathrm{I}$ for $2 \mathrm{~h}$ at $37^{\circ} \mathrm{C}$ to digest the parental DNA, purified from a $1 \%$ agrose gel by using QIAEX ${ }^{\circledR}$ II Gel Extraction Kit (Qiagen, Valencia, CA, USA), ligated, and transformed into $100 \mu \mathrm{L}$ competent Top 10 E. coli cells (Invitrogen, Carlsbad, CA, USA). After a mini-prep screen to identify candidate correctly deleted plasmids based on size, such plasmids were sequenced.

To test the method, we used a $4.8-\mathrm{kb}$ plasmid ( $\beta$-336) and a $12-\mathrm{kb}$ plasmid $(\beta-556)$ that contain a $1.8-\mathrm{kb}$ SalI/ BamHI mouse T-cell receptor genomic fragment inserted into the $3-\mathrm{kb}$ Bluescript $^{\circledR}(\mathrm{KS}+)$ vector or the $10.2-\mathrm{kb}$ pH $\beta$ APr1-neo vector (EV-107), respectively (1). Table 1 shows the primers used for deletion. We used PfuTurbo DNA polymerase for inverse PCR because it is an enzyme mixture that minimizes unwanted mutations and permits amplification of large plasmids. PfuTurbo DNA polymerase is used in the QuikChange $^{\mathrm{TM}}$ mutagenesis kit (Stratagene), which we have modified to permit site-specific mutagenesis of large (13-kb) plasmids (8). After following the procedure described above, we sequenced plasmid DNAs prepared from individual bacterial colonies.

We found that the small $(4.8-\mathrm{kb})$ plasmid template efficiently generated positive DNA clones; over $95 \%$ of the clones contained the desired internal deletion as long as the two primers differed in length by less than $10 \mathrm{nu}$ cleotides (primer pairs P1, P3, and P4; Tables 1 and 2). However, if the difference between the two primers was 10 nucleotides or more (primer pairs P2 and P5; Tables 1 and 2 and data not shown), the clones had incorrect deletions with missed or added extra nucleotides, even though the PCR product used for cloning was an appropriate size. We also obtained similar results when we used mismatched primers with large (12-kb) plasmid templates (Table 2). Poorly matched primer pairs are problematic because it is difficult to establish an annealing temperature that will allow both primers to function. The primer with the higher $\mathrm{T}_{\mathrm{m}}$ value has a greater chance of mispriming under low-temperature conditions (3). Alternatively, if too high an annealing temperature is used, the primer with the lower $\mathrm{T}_{\mathrm{m}}$ value may not function at all.

In contrast to the $4.8-\mathrm{kb}$ plasmid, the $12-\mathrm{kb}$ plasmid typically required highly specific conditions for it to serve as an efficient template for PCR. We found that there were four major differences between our protocol and other protocols $(4,5,9)$ that we found were critical for making internal deletions in large plasmids. (i) Each inverse primer had to be 30-45 bases long and have a $\mathrm{T}_{\mathrm{m}}$ of at least $78^{\circ} \mathrm{C}$ (Primer pairs P2 and P3; Tables 1 and 2). (ii) We found that $5 \%$ dimethyl sulfoxide (DMSO) in the PCR mixture was often necessary to generate product (Table 2). DMSO inhibits secondary structure formation in both primers and template; thus, it has been widely used to improve PCR amplification (2), including amplification from long plasmid templates, which are particularly prone to having strong secondary structure (8). (iii) The PCR amplification had to be 20 cycles or less; we found that 30 cycles [as suggested by other protocols $(5,9)]$ led to unexpected point mutations (data not shown). (iv) Inclusion of the methylated substrate-specific endonuclease $D p n$ I dramatically increased the frequency of correctly deleted clones. We found that this last step is critical, as $D p n$ I preferentially digests the parental non-mutated DNA, which is methylated, and thereby dramatically increased the frequency of clones with the desired 
Table 1. Oligonucleotide Primers

\begin{tabular}{|c|c|c|c|c|}
\hline $\begin{array}{l}\text { Primer } \\
\text { Pair }\end{array}$ & Primer & $\begin{array}{c}\text { Size } \\
\text { (Nucleotides) }\end{array}$ & $\mathbf{T}_{\mathrm{m}}\left({ }^{\circ} \mathbf{C}\right)$ & $\begin{array}{l}\text { Primer Sequence } \\
\qquad\left(5^{\prime} \rightarrow 3^{\prime}\right)\end{array}$ \\
\hline \multirow[t]{2}{*}{$\mathrm{P} 1$} & MDA 791 & 36 & 78.4 & TCGGTAAGTTGGGAGCTAGTAATGAAGGGGAGGGAG \\
\hline & MDA 799 & 37 & 78.1 & CCAACTCCAGAATGAGAGAGAAATTCTCTTGGCTTGG \\
\hline \multirow[t]{2}{*}{$\mathrm{P} 2$} & MDA 912 & 23 & 61.7 & TCGGTAAGTTGGGAGCTAGTAAT \\
\hline & MDA 793 & 33 & 79.0 & CCCAGTCCCGACTGCTGGCACAGAAATATACAG \\
\hline \multirow[t]{2}{*}{ P3 } & MDA 913 & 30 & 73.2 & TCGGTAAGTTGGGAGCTAGTAATGAAGGGG \\
\hline & MDA 793 & 33 & 79.0 & CCCAGTCCCGACTGCTGGCACAGAAATATACAG \\
\hline \multirow[t]{2}{*}{ P4 } & MDA 791 & 36 & 78.4 & TCGGTAAGTTGGGAGCTAGTAATGAAGGGGAGGGAG \\
\hline & MDA 793 & 33 & 79.0 & CCCAGTCCCGACTGCTGGCACAGAAATATACAG \\
\hline \multirow[t]{2}{*}{ P5 } & MDA 914 & 43 & 82.4 & TCGGTAAGTTGGGAGCTAGTAATGAAGGGGAGGGAGCATTTCC \\
\hline & MDA 793 & 33 & 79.0 & CCAGTCCCGACTGCTGGCACAGAAATATACAG \\
\hline
\end{tabular}

Table 2. Generation of Mutant Clones by Inverse PCR

\begin{tabular}{|c|c|c|c|c|c|}
\hline $\begin{array}{l}\text { Primer } \\
\text { Pair }\end{array}$ & $\begin{array}{l}\text { Deleted } \\
\text { Fragment } \\
\text { (bp) }\end{array}$ & $\begin{array}{c}\text { Template } \\
\text { Size }^{b} \\
\text { (kb) }\end{array}$ & $\begin{array}{c}\text { DMSO } \\
(\%)\end{array}$ & $\begin{array}{c}\text { PCR } \\
\text { Product }\end{array}$ & $\begin{array}{c}\text { Deletionc } \\
\text { Efficiency } \\
(\%)\end{array}$ \\
\hline P1 & 102 & 4.8 & 0 & + & 100 \\
\hline P1 & 102 & 12 & 0 & - & - \\
\hline P1 & 102 & 12 & 5 & + & 90 \\
\hline P2 & 51 & 4.8 & 0 & + & 0 \\
\hline P2 & 51 & 12 & 5 & - & - \\
\hline P3 & 51 & 4.8 & 0 & + & 100 \\
\hline P3 & 51 & 12 & 5 & - & - \\
\hline P4 & 51 & 4.8 & 0 & + & 95 \\
\hline P4 & 51 & 12 & 5 & + & 92 \\
\hline P5 & 51 & 4.8 & 0 & + & 0 \\
\hline P5 & 51 & 12 & 5 & + & 0 \\
\hline \multirow{2}{*}{\multicolumn{6}{|c|}{$\begin{array}{l}\text { aThe standard protocol for PCR: preheating of the reaction mixture to } 95^{\circ} \mathrm{C} \text { for } 3 \\
\text { min, followed by } 18 \text { cycles of } 95^{\circ} \mathrm{C} \text { for } 45 \mathrm{~s}, 62^{\circ} \mathrm{C} \text { for } 1 \mathrm{~min} \text {, and } 68^{\circ} \mathrm{C} \text { for } 2 \mathrm{~min} / \\
\text { kb template. } \\
\text { bThe PCR templates were TCR- } \beta \text { gene constructs } \beta-336 \text { (4.8-kb plasmid) and } \\
\beta-556 \text { (12-kb plasmid). }\end{array}$}} \\
\hline & & & & & \\
\hline \multicolumn{6}{|c|}{$\begin{array}{l}\text { CThe PCR product was digested with Dpnl and purified by } 1 \% \text { agrose gel with } \\
\text { the QIAEX II Gel Extraction Kit and then ligated and transformed. After } \\
\text { mini-prep screen the positive clones were sequenced. The deletion efficiency } \\
\text { is the percentage of positive clones containing the desired internal deletion. }\end{array}$} \\
\hline
\end{tabular}

deletion (6). When appropriate conditions were used, $90 \%-100 \%$ of the positive clones contained the desired internal deletion (Table 2).

A widely used approach to generate deletions is the ExSite ${ }^{\mathrm{TM}}$ PCR-Based Site-Directed Mutagenesis Kit (Stratagene), which can be used to introduce deletions in small (approximately 6-kb) plasmids in four steps. The kit's instructions indicate that the Stratagene protocol can also engender deletions in plasmids of $10 \mathrm{~kb}$ or longer if TaqPlus Long enzyme is used. However, unlike our protocol, no specific instructions for performing long PCR are included. Moreover, the accuracy of TaqPlus Long DNA polymerase is five times lower than that of the PfuTurbo DNA polymerase used in our protocol. Even for deletions from small plasmids (approximately 6-kb), we believe our protocol is a significant improvement over the ExSite kit in the following respects: (i) the PfuTurbo DNA polymerase in our protocol is about 3-fold more accurate than the ExSite DNA polymerase blend used in the ExSite kit; (ii) the ExSite kit requires more than 100 times more DNA template $(8 \mu \mathrm{g})$ than our protocol requires $(50 \mathrm{ng}$ ); (iii) the PCR products generated by the ExSite DNA polymerase blend in the ExSite kit requires cloned $P f u$ DNA polymerase to remove extended bases on the $3^{\prime}$ ends, whereas the blunt-end PCR products generated in our protocol can be direct- 
ly ligated; (iv) in the ExSite kit protocol, there is a high probability of cloning non-specific DNA fragments, as the PCR product is directly ligated without purification; (v) the ExSite kit requires the use of Epicurian Coli XL1-Blue Supercompetent bacterial cells, which are expensive, sensitive to freezing and thawing, and require particular conditions for transformation; and (vi) unlike our protocol, the ExSite kit does not provide specific criteria for selecting primers that efficiently amplify PCR products from long plasmid templates to generate deletion mutants.

In conclusion, we provide in this report a highly efficient $(90 \%-100 \%)$ and convenient protocol for the deletion of large fragments from either small or large plasmids by one-step cloning. To our knowledge, this is the first report of a site-specific deletion method that can be performed on large (12-kb) plasmids in a single step.

\section{REFERENCES}

1.Carter, M.S., S. Li, and M.F. Wilkinson. 1996. A splicing-dependent regulatory mechanism that detects translation signals. EMBO J. 15:5965-5975.

2.Cheng, S., C. Fockler, W.M. Barnes, and R. Higuchi. 1994. Effective amplification of long targets from cloned inserts and human genomic DNA. Proc. Natl. Acad. Sci. USA 91:5695-5699.

3.Dieffenbach, C.W., T.M.J. Lowe, and G.S. Dveksler. 1995. General concepts for PCR primer design, p. 133-142. In C.W. Dieffenbach and G.S. Dveksler (Eds.), PCR Primer: A Laboratory Manual. CSH Laboratory Press, Cold Spring Harbor, NY.

4.Imai, Y., Y. Matsushima, T. Sugimura, and M. Terada. 1991. A simple and rapid method for generating a deletion by PCR. Nucleic Acids Res. 19:2785.

5.Kaluz, S., M. Kaluzova, and J. Pastorek. 1999. Inverse PCR-generated internally deleted constructs for direct characterization of promoter regulatory regions. BioTechniques 26:446-450.

6.Li, S. and M.F. Wilkinson. 1997. Site-directed mutagenesis: a two-step method using PCR and DpnI. BioTechniques 23:558-590

7.Ray, F.A. and J.A. Nickoloff. 1992. Site-specific mutagenesis of almost any plasmid using a PCR-based version of unique site elimination. BioTechniques 13:342-348.

8.Wang, J. and M.F. Wilkinson. 2000. Site-directed mutagenesis of large (13-kb) plasmids in a single-PCR procedure. BioTechniques 29:976-978

9.Xu, Y. and Z. Gong. 1999. Adaptation of inverse PCR to generate an internal deletion. BioTechniques 26:639-641.
Received 28 March 2001; accepted 23 July 2001.

This research was supported by National Science Foundation grant no. MCB9808936 and National Institutes of Health grant nos. GM58595 and CA78023. Address correspondence to Dr. Miles F. Wilkinson, Department of Immunology, Box 180, The University of Texas M.D. Anderson Cancer Center, 1515 Holcombe Blvd., Houston, TX 77030,USA.e-mail: mwilkins@mail.mdanderson.org

\section{Jun Wang and Miles F. Wilkinson}

The University of Texas M.D. Anderson Cancer Center Houston, TX, USA

For reprints of this or any other article, contact Reprints@BioTechniques.com

\section{Swapping of Functional Domains Using a Chimeric Monster Deletion Muta- genesis Strategy}

\author{
BioTechniques 31:724-728 (October 2001)
}

Site-directed mutagenesis is an effective method to determine the function of amino acid and nucleotide residues within protein and RNA molecules. Systematic site-directed mutagenesis for scanning of larger regions has proven useful when only limited structural information is available (2). A variation of the site-directed mutagenesis approach is the swapping of entire domains between two related molecules to determine their unique functional differences. For domains that correspond up to several hundred base pairs, it can be difficult to introduce mutations over these larger regions for the generation of chimeric molecules, as it requires de novo gene synthesis or multiple mutagenesis steps followed by sequence verification at each step. Common restriction enzyme cutting sites for swapping domains between two related genes are rarely available and always predetermined. A relatively time-consuming method for changing large DNA segments involves preparation of uracil-containing ssDNA templates and asymmetric PCRs (7). PCR of two overlapping fragments and extension after annealing at the overlap (3) is another widely used approach to generate hybrid genes, but it is critically dependent on primer design and annealing temperatures used in amplifications of the desired DNA fragments. Here, we describe a robust strategy for generating chimeric molecules effectively and precisely. As in PCR of overlapping fragments (3), this approach is effective in the absence of convenient restriction enzyme cutting sites.

In the example described here, our aim was to construct chimeric signal recognition particle (SRP) RNA molecules in which the large domains (LDs) were exchanged precisely between human and Methanococcus jannaschii genes (Figure 1). Previous studies demonstrated that $M$. jannaschii SRP RNA bound two polypeptides, proteins 